\title{
EVOLUÇÃO DOS ESPOROCISTOS DE SCHISTOSOMA MANSONI SAMBON, 1907 EM BIOMPHALARIA GLABRATA (SAY, 1818) E BIOMPHALARIA TENAGOPHILA (D'ORBIGNY, 1835)
}

Ana Maria Aparecida Guaraldo* Luiz Augusto Magalhães *

Humberto de Araújo Rangel* Gilda Pareja**

\footnotetext{
GUARALDO, A.M.A. et al. Evolucão dos esporocistos de Schistosoma mansoni Sambon, 1907 em Biomphalaria glabrata (Say, 1818) e Biomphalaria tenagophila (D’Orbigny, 1835). Rev. Saúde públ., S. Paulo, 15:436-48, 1981.
}

RESUMO: Estudou-se a evoluçâo dos esporocistos de Shistosoma mansoni dns linhagens $\mathrm{BH}$ e $\mathrm{SJ}$ respectivamente em Biomphalaria glabrata e Biomphalaria tenagophila. Utilizando-se cortes histológicos foram avaliados o aspecto e número de esporocistos primários desde a primeira até a oitava sernana de infecção, a contar do dia em que cada molusco foi exposto a 100 miracídios. No decorrer da primeira semana constataram-se diferenças significativas entre as linhagens estudadas quanto ao número e aspecto dos esporocistos primários. A distribuição por órgãos e a evolução dos esporocistos foi observada até a fase de formação das cercárias infectantes.

UNITERMOS: Schistosoma mansoni. Biomphalaria glabrata. Biomphalaria tenagophila. Esporocistos.

\section{INTRODUÇAO}

Informes obtidos até o presente momento revelam importantes eventos decorrentes da interação de $S$. mansoni com Biomphalaria glabrata (Say, 1818) e Biomphalaria tenagophila (D'Orbigny, 1835). Mediante estudos efetuados com estas espécies, alguns autores têm demonstrado que, nos exemplares suscetiveis à infecção, os esporocistos desenvolvem-se quase sem reação tecidual do molusco. Em caramujos resistentes, a destruição dos parasitas está freqüentemente associada à encapsulação do organismo invasor por amebócitos. A incompatibilidade entre molusco e trematódeo traduz-se pela reação celular aos esporo- cistos reconhecidos como corpos estranhos (Maldonado e Acosta-Matienzo 20, 1947; Files e Cram ${ }^{11}$, 1949; Newton 23.25, 1952, 1954; Brooks 2, 1953; Coelho ${ }^{6.7,8}, 1954$, 1957, 1962; Cheng e Snyder 5, 1962; Pan 27,28, 1963, 1965; Tripp 38,39,40, 1961, $1970,1974$.

Experimentos, com a finalidade de estudar a infeç̧ão dos moluscos com linhagens alopátricas de $S$. mansoni, mostram que o sucesso do parasitismo parece depender basicamente da interação de fatores genéticos presentes nas populações do planorbídeo e do parasita.

* Do Instituto de Biologia da UNICAMP - Caixa Postal 1170 - 13100 - Campinas, SP - Brasil.

** Do Instituto de Matemática, Estatistica e Ciência da Computaçăo da UNICAMP - 13100 - Campinas, SP - Brasil 
GUARALDO, A.M.A. et al. Evolução dos esporocistos de Schistosoma mansoni Sambon, 1907 em Biomphalaria glabrata (Say, 1818) \& Biomphalaria tenagophila (D'Orbigny, 1835). Rev. Saude públ., S. Paulo, 15:436-48, 1981.

A primeira evidência de que a suscetibilidade dos moluscos ao $S$. mansoni é condicionada por fatores genéticos foi fornecida por Newton 24,25 (1953, 1954), testando uma colônia de $B$. glabrata de Salvador (BA) com linhagem portorriquenha do verme. Esta observação foi possível mediante seleção de caramujos por autofecundação, empregando-se um mutante albino como marcador. Nessa ocasião, esse autor também referiu-se à influência da idade do hospedeiro sobre a suscetibilidade. Tal hipótese foi confirmada, vinte anos depois, pelos trabalhos elaborados por Richards ${ }^{35}$ (1973), que provou a possibilidade de caramujos jovens suscetíveis tornarem-se resistentes quando adultos. Demonstrou ainda que o caráter resistência, adquirido na maturidade, é determinado por um único gene dominante, com herança mendeliana. Richards e Merritt ${ }^{34}$, em 1972, utilizando a mesma colônia parental adotada por Newton, concluiram que a suscetibilidade de moluscos jovens é controlada por um complexo de quatro ou mais fatores, assinalando a presença de genes que condicionam a resistência também nos exemplares suscetíveis.

Por outro lado, os resultados de Kagan e Geiger ${ }^{12}$ (1965) enfatizaram a importância da constituição genética do miracídio, atuando sobre a variação nos índices de infecção de $B$. glabrata albina.

Outro relevante ponto de vista foi assinalado por Files e $\mathrm{Cram}^{11}$ (1949), que ressaltaram a complexidade das inter-relações estabelecidas entre hospedeiro e parasita, no teste de suscetibilidade frente a diversas linhagens de $S$. mansoni, com caramujos provenientes da Libéria, Egito, Porto Rico, Venezuela e Brasil. Admitiram a existência de diferenças fisiológicas, intra e interespecificas, entre os vermes de áreas endêmicas diferentes.

A necessidade de um ajuste fisiológico entre molusco e verme ficou bem demonstrada por Paraense e Corrêa ${ }^{31}$ (1963), na constatação de que $S$. mansoni, adaptado à $B$. glabrata de Minas Gerais, apresentou resistência à infecção quando colocado frente a $B$. tenagophila de São Paulo e vice-versa. Com base neste fato, demonstraram a existência de duas linhagens de S. mansoni: uma de Belo Horizonte $(\mathrm{BH})$ que requer $B$. glabrata e outra de São José dos Campos (SJ) que requer $B$. tenagophila. Para cada espécie de hospedeiro, $O$ indice de infecção seria condicionado pela variação na freqüência de genes responsáveis pela suscetibilidade e resistência, presentes numa determinada população de molusco ( $\mathrm{Pa}$ raense Corrêa ${ }^{32}, 1963$ ).

Outra abordagem deste problema foi aventada por Magalhães ${ }^{15}$ (1966), ajustando uma interpretação alternativa, quanto à especificidade envolvida no complexo molusco-trematódeo; o autor acredita que a suscetibilidade ao esquistossomo representa a aptidão de um molusco com genótipo favorável, frente a um miracídio portador de genótipo pré-adaptado às suas condições. Nesta situação, o mesmo exemplar de caramujo pode não ser suscetivel a outro miracidio pertencente à mesma população.

As implicações do raciocínio acima referido estendem-se ao campo da epidemiologia, pois fornecem subsídios que justificam a implantação da doença no Vale do Rio Paraiba do Sul (SP), região onde não se tinha registro de casos autóctones até 1956. Nesta época, B. tenagophila era reconhecida como responsável pela manuntenção de focos ativos no Rio de Janeiro (Deane e col.10, 1953), Niterói (Martins ${ }^{21}$, 1957), Santos (Moura 22, 1945) e outros pontos do litoral paulista.

Conforme o relato de Piza e col. ${ }^{33}$ (1959), apesar das autoridades sanitárias terem alertado sobre a presença de casos autóctones na região do Vale do Rio Paraíba do Sul (Corrêa e col. ${ }^{9}$, 1956), não foi avaliada de imediato a grande importância epidemiológica deste achado, uma vez que o transmissor exclusivo da região, B. tena- 
GUARALDO, A.M.A. et al. Evolução dos esporocistos de Schistosoma mansoni Sambon, $1907 \mathrm{em}$ Biomphalaria glabrata (Say, 1818) e Biomphalaria tenagophila (D'Orbigny, 1835). Rev. Saúde públ., S. Paulo, 15:436-48, 1981.

gophila, apresentava alto grau de resistência à infecção em laboratório (Coelho 7,1957 ). Prevaleceu então o conceito de que esta espécie não teria condições para contribuir de maneira efetiva na disseminação da parasitose.

Infelizmente não foi o que ocorreu e a esquistossomose assumiu o caráter de doença profissional, imposta pelas circunstâncias propicias do ambiente, destacando-se, em particular, o tipo de irrigação adotada no cultivo de arroz. O constante contato dos lavradores com água contaminada e a presença de grande número de moluscos foram os fatores determinantes na indução de melhor ajuste entre hospedeiro e parasita. Só após muitos esforços, ficaram comprovadas a gravidade $e$ a extensão do problema, numa área de grande expressão econômica.

Admitindo-se que o $S$. mansoni esteja em fase inicial de adaptação no Vale do Rio Paraiba do Sul, torna-se oportuno o estudo comparativo das linhagens $\mathrm{BH}$ e SJ, na tentativa de elucidar alguns fenômenos relacionados com a evolução do parasitismo.

Várias etapas deste estudo foram realizadas no laboratório do Depto. de Parasitologia da Universidade Estadual de Campinas. Destacamos alguns resultados obtidos em camundongos infectados experimentalmente com linhagens $\mathrm{BH}$ e SJ. Cercárias da linhagem mineira de $S$. mansoni apresentaram maior capacidade de penetração no tegumento de roedores, provocando uma patologia hepática mais severa do que aquela induzida pelo verme de São José dos Campos (Magalhães e Carvalho ${ }^{18}, 1969$; Magalhães e Carvalho ${ }^{17}$, 1973; Magalhães e col.16, 1975; Lemos Neto e col. ${ }^{13}$, 1978). Estudando a morfologia dos vermes adultos das linhagens $\mathrm{BH}$ e SJ, Magalhães e Carvalho 18 (1973) verificaram diferenças significativas nas determinaçōes do comprimento, na distância entre as ventosas oral e acetabular, assim como na distância entre a extremidade distal das gônadas e a parte anterior dos vermes. Ficou demonstrado ainda que 0 número de testículos de $S$. mansoni da linhagem mineira é superior ao apresentado pela linhagem paulista. Se realmente existe maior contribuição de uma das linhagens na evolução da patologia no hospedeiro definitivo, parece válida a suposição de que o comportamento no hospedeiro intermediário também possa apresentar características próprias.

Com base nestes fatos, pareceu-nos oportuno acompanhar o desenvolvimento dos esporocistos de ambas as linhagens nos respectivos hospedeiros simpátricos. A característica dominante nesta abordagem é a avaliação qualitativa e quantitativa dos esporocistos primários no decorrer da infecção.

\section{MATERIAL E METODOS}

As linhagens $\mathrm{BH}$ e $\mathrm{SJ}$ de $S$. mansoni utilizadas no experimento, foram mantidas em laboratório através de infecções simpátricas, respectivamente, de $B$. glabrata e de $B$. tenagophila, adotando-se como hospedeiro vertebrado Mus musculus albino.

Mantivemos também populações de $S$. mansoni das linhagens $\mathrm{BH}$ e $\mathrm{SJ}$ em vetores naturais, porém selecionados geneticamente para o caráter suscetibilidade. A obtenção destas populações de moluscos altamente suscetíveis às linhagens simpátricas foi possivel mediante auto fecundação em várias gerações sucessivas, conforme 0 método de Santana e col.36 (1978). Exemplares da geração $\mathrm{F} 4$ de $B$. tenagophila e da geração F3 de $B$. glabrata foram utilizados para infecção alopátrica com 15 miracídios.

Caramujos infectados individualmente com 100 miracídios das linhagens simpátricas e destinados a observação em microscópio óptico foram sacrificados por grupos, desde a primeira semana até a oitava semana após a infecção, visando a observação de diferentes estágios de evolução das larvas do esquistossomo. Após fixados, 
GUARALDO, A.M.A. et al. Evolug̣ăo dos esporocistos de Schistosoma mansoni Sambon, 1907 em Biomphalaria glabrata (Say, 1818) e Biomphalaria tenagophila (D'Orbigny, 1835). Rev. Saúde públ., S. Paulo, 15:436-48, 1981.

os moluscos eram incluídos em parafina, cortados ao micrótomo com $7 \mu \mathrm{m}$ de espessura e corados pela $\mathrm{HE}$, tricrômico de Gomori e PAS. Como controle do experimento foram utilizados moluscos não infectados. A observação dos esporocistos foi feita mediante cortes seriados em preparações previamente examinadas à lupa estereoscópica.

Para análise estatística dos dados referentes aos esporocistos adotamos testes não paramétricos (rank-test de Wilcoxon ou de Mann-Whitney).

A distribuição das larvas nos órgãos do hospedeiro foi avaliada mediante a aplicação do teste de Friedman (Snedecor $\mathrm{e}$ Cochran 37, 1967).

\section{RESULTADOS E DISCUSSAO}

Observaf̧öes sobre evolução do esporocisto primário.

No decorrer de nossas observaçōes, constatamos particularidades morfológicas nos esporocistos primários, aproveitadas para classificação destas larvas, de acordo com o critério abaixo mencionado.

Esporocisto primário é a denominação que vários autores adotam para miracídios já desprovidos de cílios e que tenham ingressado no tecido do molusco há pelo menos 24 horas.

\section{a) Esporocisto primário integro.}

A característica notável do esporocisto primário integro foi a ausência de infiltração de amebócitos em torno da larva.

As células presentes no esporocisto primário eram de duas categorias: células somáticas e células germinativas (Cheng $\mathrm{e}$ Bier ${ }^{4}$, 1972). Nesta modalidade de larva, as células somáticas apresentaram-se arredondadas, com tamanhos diversos, citoplasma discretamente basófilo, contendo finas granulações também basófilas dispostas predominantemente junto da membrana externa. $O$ núcleo das células era único e geralmente central, arredondado, ocupando aproximadamente $1 / 4$ do volume celular e nucléolo às vezes proeminente. $O$ núcleo das células germinativas apresentou-se vesicular e o citoplasma muito rico em granulações. Células somáticas e germinativas apresetaram-se, desde o primeiro dia, envoltas por uma membrana polissacarídica, demonstrável em reação citoquímica pelo PAS. Em um esporocisto primário, observou-se a presença de uma única fileira de células germinativas junto à membrana externa da larva, simulando um epitélio germinativo (Fig. 1). Esta membrana pareceu ser remanescência da parede do miracídio. $\mathrm{Na}$ microscopia óptica comum não visualizamos musculatura na parede do esporocisto; este fato explicaria a ausência de locomoção da larva. Convém ressaltar que a musculatura no esporocisto secundário apresentou-se razoavelmente desenvolvida e o tegumento dotado de pequenos espículos.

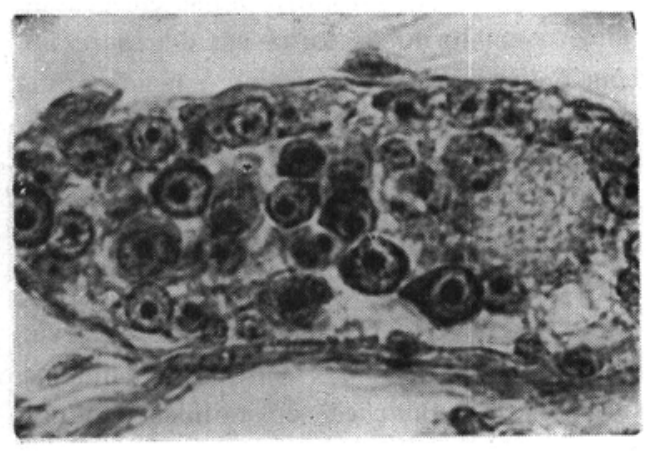

1. Biomphalaria glabrata (2 dias de infecção, Tricrómico de Gomori, $1400 \mathrm{X}$ ). Notar a organização de células germinativas junto à parede do esporocisto primário.

\section{b) Esporocisto primário degenerado ce- lular}

As células esporocisticas em degeneraçâo, na sua maioria, apresentaram núcleo pic- 
GUARALDO, A.M.A. et al. Evolução dos esporozistos de Schistosoma mansoni Sambon, 1907 em Biomphalaria glabrata (Say, 1818) e Biomphalaria tenagophila (D'Orbigny, 1835). Rev. Saúde públ., S. Paulo, 15:436-48, 1981.

nótico. O citoplasma destas células passou a ser eosinofílico e os grânulos citoplasmáticos tenderam a se agrupar (Fig. 2).

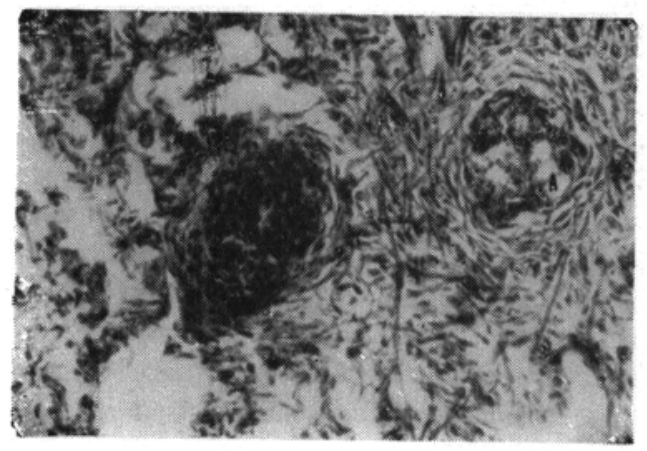

2. Biomphalaria tenagophila (1 dia de infeç̧ão, Tricrómico de Gomori, $90 \mathrm{X}$ ). Esporocistos primários em processo degenerativo no pé do molusco. Infiltrado amebocitário em disposiçăo concéntrica ao redor da larva em degeneração (A).

Os amebócitos concentraram-se em grande número em torno da larva em degeneração, com o fim aparente de isolar o tecido adjacente. O núcleo dos amebócitos, assim como seu citoplasma, era alongado, simulando o aspecto de uma fibra semelhante ao fibroblasto. Estas modificações amebocitárias ocorreram quando as células de defesa estavam em intimo contato com a larva. No citoplasma destas células fagocitárias surgiram granulações eosinofílicas, talvez produto de secreção.

Quando se tratava de infecções antigas, tornava-se difícil afirmar se a disposição assumida pelos amebócitos era decorrente de reação em torno de larva em processo de desintegração ou de outro corpo estranho, pois as células esporocísticas alteravam-se e na maior parte dos casos, desapareciam. Por isso, propomos uma terceira categoria de esporocistos que denominamos ACFI.UI.ARES.

\section{c) Esporocisto primário degenerado ace- lular}

Esta condição apresentou-se sob duas formas, dependentes do grau de degeneração. Quando as larvas encontravam-se ainda em processo ativo de degeneração, as células esporocísticas perdiam suas características normais para tornarem-se granulosas e eosinofilicas, ficando reduzidas a simples massa amorfa envolta por uma coroa de amebócitos. Quando as larvas estavam em adiantado estágio degenerativo, restavam apenas amebócitos envolvendo uma região, que aos poucos ficava preenchida por tecido do tipo conjuntivo, notando-se, porém, alguns vacúolos no local que, supostamente, havia sido ocupado pela larva.

Nossos dados, referentes à localização dos esporocistos nos tecidos, estão de acordo com os assinalados por Maldonado e Acosta-Matienzo 20 (1947), Olivier e Mao 2a (1949), Coelho $\tau$ (1957) e Pan 28 (1965).

A distribuição dos esporocistos primários nos órgãos do hospedeiro foi observada por vários autores. Lutz ${ }^{14}$ (1919) havia registrado a preferência dos miracídios pelo tentáculo, fato confirmado por Brumpt ${ }^{3}$ (1940); Mandonado e Acosta-Matienzo 20 (1947) e Coelho ? (1957). Entretanto, as duas espécies de moluscos por nós examinadas apresentaram maior incidência dos esporocistos primários na região podal, conforme ficou demonstrado pela análise estatística.

Quanto à distribuição dos esporocistos primários nos diferentes órgãos (Tabela 1), no decurso da primeira semana de infecção, verificou-se que eles se localizaram em número decrescente nos órgãos que relacionamos a seguir, na ordem de frequiência de parasitos: pé, cabeça, tentáculos, colar do manto, manto e outras regiōes, restringindo-se portanto, às áreas mais expostas a infecção. 
GUARALDO, A.M.A. et al. Evolução dos esporocistos de Schistosoma mansoni Sambon, $1907 \mathrm{em}$ Biomphalaria glabrata (Say, 1818) e Biomphalaria tenagophila (D'Orbigny, 1835), Rev. Saúde públ., S. Paulo, 15:436-48, 1981.

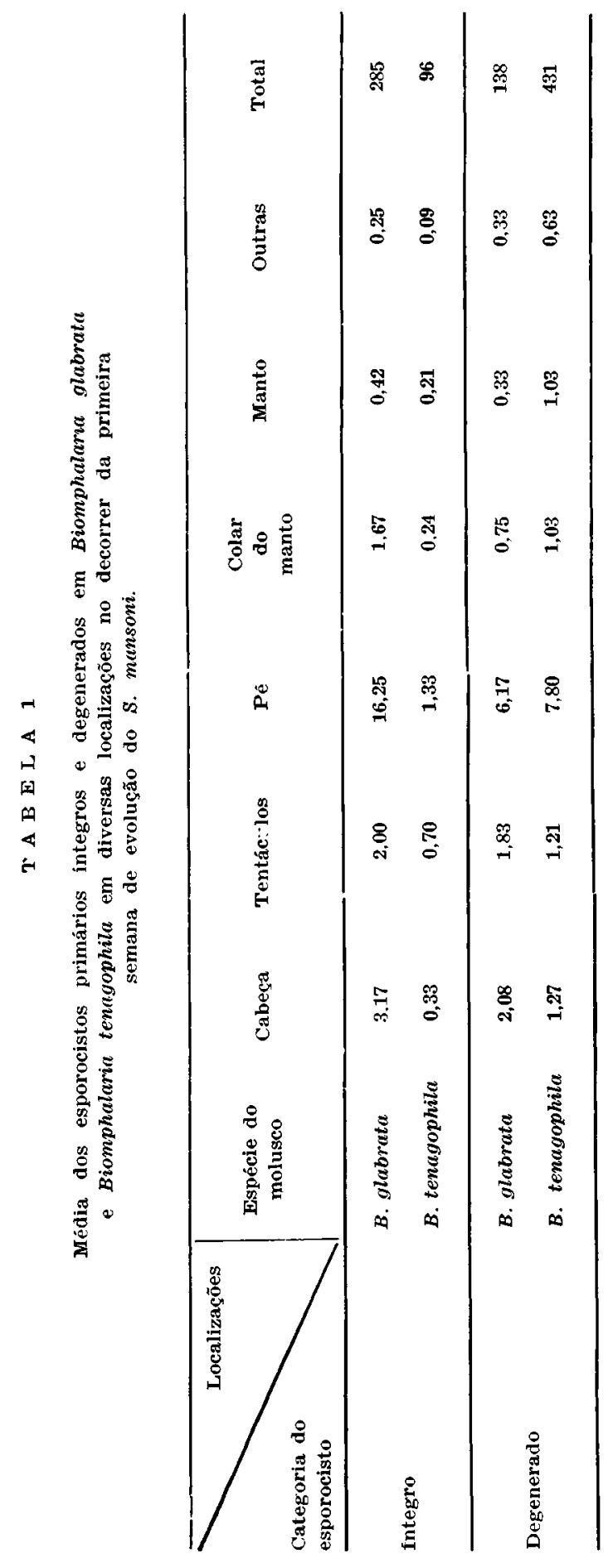


GUARALDO, A.M.A. et al. Evolução dos esporocistos de Schistosoma mansoni Sambon, $1907 \mathrm{em}$ Biomphataria glabrata (Say, 1818) e Biomphalaria tenagophila (D'Orbigny, 1835). Rev. Saúde puibl., S. Paulo, $15: 436-48,1981$.

Quando comparamos a distribuição de esporocistos primários íntegros e degenerados por órgão, os resultados superpuseram-se aos obtidos quando se considerou a totalidade de esporocistos. Tal verificação permitiu concluir que não houve, de modo especifico, um órgão que oferecesse melhor condição para o desenvolvimento do esporocisto primário e, por conseguinte, os diferentes órgãos comportaram-se de igual maneira com relação aos esporocistos primários, durante a primeira semana de evolução. A permanência dos esporocistos primários na região de penetração pode perdurar várias semanas, possivelmente até que se esgotasse sua capacidade reprodutiva. Mesmo em moluscos suscetiveis, observou-se de modo geral, processo degenerativo parcial ou total nos esporocistos primários mais antigos, ainda contendo esporocistos secundários em seu interior, particularmente após a $7^{\text {a }}$ semana de infecção.

A destruiçāo das larvas ocorreu principalmente nos três primeiros dias de pós-infecção. Neste estágio podemos determinar a condição dos esporocistos primários e ainda detetamos a totalidade de larvas que atingiram os tecidos, incluindo aquelas que estavam sendo absorvidas. Neste periodo, em 8 planorbideos infectados com a linhagem $\mathrm{BH}$, observou-se que, dos 800 miracídios expostos aos moluscos, foram encontrados apenas 298 nos tecidos, o que acarretou uma taxa de penetração equivalente a $37,25 \%$ para a linhagem mineira. Observamos que $29,5 \%$ dos miracídios da linhagem $\mathrm{BH}$ apresentaram-se degenerados. Portanto, o número de larvas $\mathrm{BH}$ que pareceu garantir o sucesso da infecção em B. glabrata correspondeu a $70,5 \%$ do total encontrado nos tecidos.

Aplicando-se o mesmo raciocínio para $B$. tenagophila, parasitada por $S$. mansoni da linhagem SJ, em 7 exemplares examinados neste periodo, 0 índice de penetração de miracídios foi de apenas $17,4 \%$, sendo que $98,4 \%$ dos esporocistos primários apresentaram-se degenerados, ou seja, a infecção foi garantida por $1,6 \%$ das larvas presentes em $B$. tenagophila.

Verificamos ainda que, em $15,15 \%$ dos casos, B. tenagophila mostrou-se capaz de destruir a totalidade dos esporocistos primários durante a primeira semana de infecção. Nos exemplares nos quais não foi sustada a infecção, $81,8 \%$ dos esporocistos tornaram-se degenerados; neste caso, $27 \%$ dos esporocistos eram acelulares. O comportamento de $B$. glabrata apresentou-se completamente diferente, pois, ao final da primeira semana, a totalidade dos moluscos era portadora de larvas viáveis, ao lado de $32,6 \%$ de esporocistos em vias de degeneração.

$\mathrm{Na}$ análise estatística efetuada com esporocistos primários e relacionada com o comportamento destes, no decorrer da primeira semana, verificamos que os valores médios para esporocistos primários íntegros e totais foram significativamente maiores em $B$. glabrata do que em $B$. tenagophila, ao nivel de 1\%. Na linhagem $\mathrm{SJ}$, o número de esporocistos degenerados e acelulares, durante o mesmo periodo, mostrou-se significativamente maior em relação à linhagem $\mathrm{BH}$ (Tabela 2).

Verificou-se que, duas semanas após a infecção, não houve diferença significativa entre as modalidades de esporocistos primários nas duas espécies. Na terceira semana, a diferença entre esporocistos primários integros e totais, de ambas as linhagens, foi significativa ao nivel de $1 \%$, apresentando-se maior na linhagem $\mathrm{BH}$.

No último periodo analisado, isto é, o compreendido entre o $35^{\circ}$ ao $70^{\circ}$ dia após a infecção, encontramos maior média numérica de esporocistos primários em $B$. glabrata. Esta diferença foi conseqüência da presença de maior número de esporocistos primários degenerados. Tal acontecimento explica-se pelo fato de que, neste periodo, os esporocistos primários precocemente degenerados em $B$. tenagophila já tinham sido absorvidos. 
GUARALDO, A.M.A. et al. Evolução dos esporocistos de Schistosoma mansoni Sambon, 1907 em Biomphalaria glabrata (Say, 1818) e Biomphalaria tenagophila (D'Orbigny, 1835). Rev. Saúde puibl., S. Paulo, 15:436-48, 1981.

\section{T A B E L A 2}

Média de esporocistos primários integros (EI), degenerados (ED) e totais (ET) encontrados nos diferentes períodos da infecção em Biomphalaria glabrata e Biomphalaria tenagophila.

\begin{tabular}{|c|c|c|c|c|c|}
\hline $\begin{array}{l}\text { Dias após } \\
\text { exposição }\end{array}$ & Espécie & $\begin{array}{l}\text { Número de } \\
\text { moluscos } \\
\text { examinados }\end{array}$ & EI & ED & $\mathbf{E T}$ \\
\hline \multirow{2}{*}{1} & B. glabrata & 2 & 14,0 & 27,0 & 41,0 \\
\hline & B. tenagophila & 4 & 0,0 & 20,0 & 20,0 \\
\hline \multirow{2}{*}{2 e 3} & B. glabrata & 7 & 26.1 & 4.9 & 31.0 \\
\hline & B. tenagophila & 3 & 0.7 & 13,3 & 14.0 \\
\hline \multirow{2}{*}{5,6 e 7} & B. glabrata & 3 & 24.7 & 16.7 & 41.4 \\
\hline & B. tenagophita & 26 & 3.6 & 11.9 & 15,5 \\
\hline \multirow{2}{*}{14} & B. glabrata & 4 & 0.8 & 0.3 & 1.1 \\
\hline & B. tenagophila & 12 & 2,2 & 2.4 & 4.6 \\
\hline \multirow{2}{*}{21.} & B. glabrata & 7 & 5,1 & 2.3 & 7.4 \\
\hline & B. tenagophila & 5 & 0,2 & 0.4 & 0,6 \\
\hline \multirow{2}{*}{27} & B. glabrata & 6 & 3,7 & 1.5 & 5,2 \\
\hline & B. tenagophila & $2 *$ & 13,5 & 1,5 & 15,0 \\
\hline \multirow{2}{*}{35 a 70} & B. glabrata & 7 & 4,0 & 5,6 & 9.6 \\
\hline & $B$, tenagophila & 11 & 0,7 & 1,4 & 2,1 \\
\hline
\end{tabular}

Foi feita tentativa para determinação de uma função matemática capaz de expressar a correlação fornecida pelo número de esporocistos primários (íntegros e degenerados) e tempo de infecção, para cada linhagem de esquistossomo. Do ponto de vista estatisticn, pareceria que a hipérbole seria a representação mais compativel com o fenômeno biológico. Entretanto, o ajuste hiperbólico mostrou-se insatisfatório, compro- vando apenas que existe regressão com o decorrer do tempo, nas duas espécies de molusco. Tentamos ajustar uma curva exponencial e o resultado foi desfavorável, devido à grande dispersão dos dados e do pequeno número de observações disponiveis em cada período de infecção.

Ressaltamos, entretanto, que ao final de uma semana após exposição aos miracídios, $B$. tenagophila apresentou $59 \%$ dos espo- 
GUARALDO, A.M.A. et al. Exolução dos esporocistos de Schistosoma mansoni Sambon, 1907 em Biomphalaria glabrata (Say, 1818) e Biomphalaria tenagophila (D'Orbigny, 1835). Rev. Saúde públ., S. Paulo, 15:436-48, 1981.

rocistos degenerados, enquanto que $B$. glabrata mostrou apenas $11,8 \%$ de formas degeneradas. A resistência de $B$. tenagophila tem sido apontada por outros autores (Coelho ', 1957; Coelho ${ }^{8}$, 1962; Paraense e Corrêa ${ }^{30.31}$, 1963; Bastos e col.11, 1978; Santana e col. ${ }^{31}, 1978$ e Paraense e Corrêa ${ }^{29}, 1978$ ).

$\mathrm{O}$ ajuste físiológico entre caramujo e trematódeo estaria na dependência do comportamento do molusco durante a infecção e condicionado pela constituição genética do molusco. Entretanto, é muito provável que este não seja o único mecanismo atuante no complexo relacionamento hospedeiro-parasita. Parece-nos que o fator determinante do sucesso do parasitismo se refere à constituição genética de cada espécie, pois na infecção alopátrica de moluscos, geneticamente selecionados para o caráter suscetibilidade, não foram detectadas reações amebocitárias em torno das larvas. Talvez, neste processo seletivo, os moluscos suscetiveis ao S. mansoni também apresentem menor capacidade de reconhecimento a outros agentes estranhos.

Parece lícito supor que o molusco paulista, resistente à infecção, seja capaz de dar origem a maior número de amebócitos, ou que estas células possuam maior capacidade de agressão. Não se pode, também, excluir a possibilidade da larva da linhagem SJ atrair maior número de células de defesa do hospedeiro.

O sucesso obtido da infecção alopátrica, em planorbideos geneticamente selecionados, reforça a hipótese de que os moluscos deixam de reconhecer a larva alopátrica como estranha. Este fato ocorreu tanto em B. glabrata como em B. tenagophila. Por outro lado, a resistência adquirida por seleção também se manteve para a linhagt m alopátrica de $S$. mansoni.

\section{Aspectos gerais da evolução dos esporo- cistos}

A medida que o número de células do esporocisto aumenta, o corpo do esporo- cisto tende a se alongar. Encontramos esporocistos primários que apresentaram uma constrição na zona mediana, de maneira a dividí-los em dois compartimentos. A transformação do esporocisto primárjo em secundário foi gradual e este processo pode ter inicio já na primeira semana de desenvolvimento do parasito. Dai em diante, o número de septos parietais aumentou, dividindo o esporocisto primário em vários compartimentos com áreas irregulares, preenchidas por células esporocísticas (Fig. 3 ). Neste estágio, a multiplicação celular foi abundante e pareceu não ter havido interrupção num período cuja duração variou entre 14 e 21 dias, ocasião em que se observou a presença de esporocistos secundários aptos à migração. Nos primeiros estágios, os esporocistos secundários apresentaram-se como aglomerados celulares sen membrana envolvente. Posteriormente, tais aglomerados assumiram a forma esférica, já envoltos por fina membrana. As fases subseqüentes foram caracterizadas por alongamento da larva e aparecimento de sistema excretor, constituído por duas células-flamas alojadas, simetricamente, na porção mediana da larva e próximas do tegumento do esporocisto secundário.

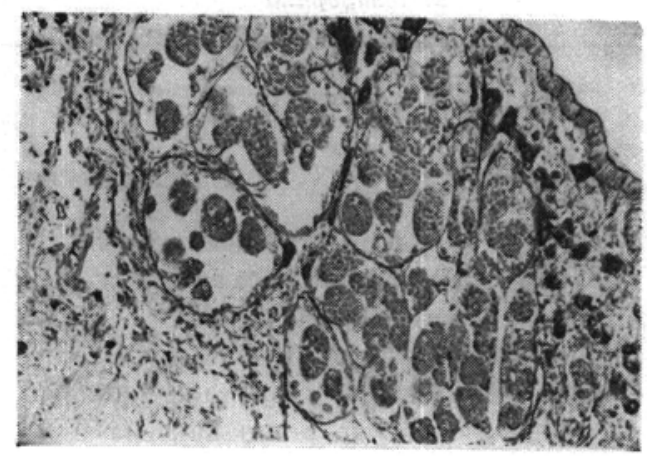

3. Biomphalaria tenagophila (21 dias de infecção, PAS-Hematoxilina, $50 \mathrm{X}$ ). Fsporocistos secundários integros no manto. A parede dos esporocistos secundários á PAS positiva. 
GUARALDO, A.M.A. et al. Evolução dos esporocistos de Schistosoma mansoni Sambon, 1907 em Biomphalaria glabrata (Say, 1818) e Biomphalaria tenagophila (D'Orbigny, 1835). Rev. Saúde públ., S. Paulo, 15:436-48, 1981.

Foi notável a evolução assincrônica de esporocistos, principalmente nos moluscos de Belo Horizonte. Desconhece-se a causa determinante do fenômeno. Teria sido decorrente da expressão de potencial germinativo diferente de cada miracidio ou resultante das diferenças quanto ao ritmo de crescimento apresentado pelas larvas. Em conseqüência da assincronia do desenvolvimento, não pudemos avaliar o ritmo de crescimento das linhagens $\mathrm{BH}$ e SJ. Notou-se frequientemente a organização de um epitélio germinativo, na superfície interna da parede do esporocisto secundário maduro, sugerindo continua produção de células germinativas destinadas à formação das cercárias. Além disso, dentro do mesmo esporocisto, houve assincronia no desenvolvimento das cercárias.

Em nosso estudo pudemos observar esporocistos primários degenerados ainda não absorvidos, na $10^{\mathrm{k}}$ semana de infecção. E possível que nestes casos tenha havido um retardamento na evolução das larvas, associado a fatores fisiológicos ou relacionados com o meio ambiente.

Pareceu existir um estimulo que induz a separação do esporocisto secundário do primário, migrando através do tecido conjuntivo frouxo ou sendo transportado pelo fluxo hemolinfático. Esta migração dos esporocistos secundários processou-se por pequenos grupos e teve início a partir do $13^{\text {? }}$ dia de infecção podendo demorar alguns dias. Foi impossível avaliar o tempo necessário para que alcançassem órgãos mais propicios ao desenvolvimento das cercárias, mesmo porque foi grande o número de esporocistos primários resultantes de uma única exposição. Tal circunstância associada ao desenvolvimento assincrônico, impossibilitou a identificação da procedência das larvas migrantes. A nosso ver, pareceu existir necessidade da chegada dos esporocistos secundários ao hepatopâncreas e ovotestis, para que se iniciasse a diferenciação das cercárias, pois só nestas regiões é que se observou a presença de esporocistos secundários maduros com cercárias bem diferenciadas. No caso de $B$. glabrata, o fenômeno da diferenciação de cercárias teve início na quinta semana de infecção, enquanto que para $B$. tenagophila, nos poucos exemplares parasitados, foram vistas cercárias diferenciadas a partir da oitava semana de penetração dos miracídios.

Durante o desenvolvimento dos esporocistos primários, os danos celulares provocados pelos parasitas foram reversiveis $\mathrm{e}$ não acarretaram morte do hospedeiro. Porém, foi grande a mortalidade dos moluscos que se encontravam na fase de eliminação de cercárias. Nesta fase, a sobrevivência dos planorbideos poderia ser afetada por vários fatores: ação de determinados componentes metabólicos liberados pelas cercárias; compressão dos tecidos pelos parasitas; formação de êmbolos na hemolinfa, devido à eliminação simultânea de grande número de larvas infectantes.

Encontramos formas jovens e maduras de esporocistos em todo o corpo do mulusco. Raramente tivemos oportunidade $d t$ observar cercárias plenamente evoluidas en esporocistos secundários situados na regiāo cefalopodal do hospedeiro. Quando este fato ocorria, coincidia com parasitismo intenso do molusco, o que pode dificultar a migra. ção dos esporocistos secundários para órgãos internos. Verificamos que, nestes casos de maturação ectópica, foi habitual o encontro de afluxo de amebócitos em torno do esporocisto maduro.

\section{CONCLUSÖES}

A evolução dos esporocistos primários e secundários do $S$. mansoni das linhagens $\mathrm{BH}$ e SJ em moluscos simpátricos foi avaliada mediante observações de cortes histológicos dos planorbídeos sacrificados em diferentes estágios da infecção. Desta maneira, as preparações, examinadas em microscopia óptica comum, foram obtidas a 
GUARALDO, A.M.A. et al. Evolução dos esporocistos de Schistosoma mansoni Sambon, 1907 em Biomphalaria glabrata (Say, 1818) e Biomphalaria tenagophila (D'Orbigny, 1835). Rev. Saúde públ., S. Paulo, 15:436-48, 1981.

intervalos semanais até a oitava semana após o contato de cada planorbídeo con 100 miracídios.

Os resultados referentes à primeira semana de infecção revelaram que:

- B. glabrata foi portadora de maior número de esporocistos primários viáveis. Em B. tenagophila predominaram esporocistos primários degenerados, envolvidos por infiltrados amebocitários. No $3^{\circ}$ dia de infecção, $B$. glabrata apresentou $70,5 \%$ dos esporocistos primários íntegros, enquanto que em $b$. tenagophila apenas $1,6 \%$ dos esporocistos primários presentes nos tecidos apresentaram-se viáveis (em condições de progredir no processo evolutivo no hospedeiro intermediário).

- os miracidios da linhagem BH apresentaram maior capacidade de penetração que os da linhagem SJ.

- não houve diferença significativa entre as linhagens, quanto à distribuição dos esporocistos primários nos tecidos. A regiăo podal mostrou maior número de esporocistos primários, seguindo-se ca- beça, tentáculos, colar do manto, manto e outros órgãos.

- observou-se grande assincronia no desenvolvimento de esporocistos primários e secundários nas duas espécies de moluscos.

No decorrer das semanas subseqüentes da infecção observou-se que:

- a diferenciação das cercárias tem início na $5^{a}$ semana de evolução em $B$. glabrata e na $8^{\text {a }}$ semana de infecção de $B$. tenngophila.

- foi frequiente a ocorrência de processo degenerativo em esporocistos com mais de 7 semanas após a infecção, sobretudo em esporocistos secundários desenvolvidos no mesmo local ocupado pelo esporocisto primário que thes deu origem.

- nas infecções alopátricas, moluscos geneticamente selecionados para o caráter suscetibilidade, passaram a não reconhecer a linhagem alopátrica como estranha. Nestes moluscos não foi observada reação amebocitária em torno dos esporocistos.

GUARALDO, A.M.A. et al. [The evolution of sporocysts of schistosoma mansoni, Sambon, 1907, in Biomphalaria glabrata (Say, 1818) and in Biomphalaria tenagophila (D'Orbigny, 18j5) ]. Rev. Saúde públ., S. Paulo, 15:436-48, 1981.

AJSTRACT: The evolution of sporocysts of Schistosoma mansoni strains from BH and SJ in their respective vector snails was studied, and aspect and the number of the initial sporocysts were verified during the first weeks of infection. Significant differences were noticed in the number of sporocysts in both strains. Aspects of their development were observed, as well as their distribution throughout the organs, until the cercariae were completely formed.

UNITERMS: Schistosoma mansoni. Biomphalaria glabrata. Biomphalaria tenagophila. Sporocysts. 
GUARALDO, A.M.A. et al. Evolução dos esporocistos de Schistosoma mansoni Sambon, 1907 em Biomphalaria glabrata (Say, 1818) e Biomphalaria tenagophila (D'Orbigny, 1835). Rev. Saúde públ., S. Paulo, $15: 436-48,1981$.

\section{REFERENCIAS BIBLIOGRAFICAS}

1. BASTOS, O. de C.; MAGaLHäES, L.A. RANGEL, H.A. \& PIEDRABUENA, A.E. Alguns dados sobre o comportamento parasitológico das linhagens humana $e$ silvestre do Schistosoma mansoni, no vale do Rio Paraíba do Sul, SP (Brasil). Rev. Saúde públ., S. Paulo, 12:184-99, 1978.

2. BROOKS, C.P. A comparative study of Schistosoma mansoni in Tropicorbis havanensis and Australorbis glabratus. $J$. Parasit., 39:159-65, 1953.

3. BRUMPT, E. Confirmation des observations de A. Lutz sur lésions tentaculaires de Planorbis glabratus $(=P$. guadalupensis) determinées par l'evolution sur place des miracidies de Schistosoma mansoni. C.R. Soc. Biol., $133: 625-8,1940$.

4. CHENG, T.C. \& BIER, J.W. Studies on mollr.scan schistosomiasis: an analvsis of the development of the cercaria of Schistosoma mansoni. Parasitology, 64: 129-41, 1972.

5. CHENG, T.C. \& SNYDER, R.W. Studies on host parasite relationships between larval trematodes and their hosts. I. A review. II. The utilization of the host's glycogen by the intramolluscan larvae of Glypthelmins pennsylvaniensis Cheng. and associated phenomena. Trans. Amer. microsc. Soc., 81:209-28, 1962.

6. COELHO, M.V. Ação das formas larvárias de Schistosoma mansoni sobre a reprodução de Australorbis glabratus. Publ. avul. Inst. Aggeu Magalhães, 3:39-53, 1954.

7. COEL.HO, M.V. Aspectos do desenvolvimento das formas larvais de Schistosoma mansoni em Australorbis nigricans. Rev. bras. Biol., 17:325-37, 1957.

8. COEIJHO, M.V. S*scetibilidade de Australorbis tenagophilus à infecção por Schistosoma mansoni. Rev. Inst. Med. trop. S. Paulo, 4:289-95, 1962.

9. CORREA, R.R.: CODA, D. \& OLIVEIRA U.A. Um foco autóctone de esquistossomose no Vale do Paraíba. Folia clin. biol., S. Paulo, 26:85-90, 1956.
10. DEANE, L.M.; MARTINS, R.S. \& LOBO. M.B. Um foco ativo da esquistossomose mansônica em Jacarepaguá, Distrito Federal. Rev. bras. Malar., 5:249-52, 1953.

11. FILES, V.S. \& CRAM, E.B. A study on the comparative susceptibility of snail vectors to strains of Schistosoma man. soni. J. Parasit., 35:555-60, 1949.

12. KAGAN, I.G. \& GEIGER, S.J. The suscep. tibility of three strains of Australorbis glabratus to Schistosoma mansoni from Brazil and Puerto Rico. J. Parasit., 51:622-7, 1965 .

13. LEMOS NETO, R.C.; MAGALHAES, L.A. \& PIEDRABUENA, A.E. Alguns aspectos referentes ao estudo de linhagens de Schistosoma mansoni Sambon, 1907, provenientes dos Estados de Minas Gerais e de São Paulo, Brasil. Rev. Saúde públ., S. Paulo, 12:277-90, 1978.

14. LUTZ, A. O Schistosoma mansoni e a Schistosomose segundo observações feitas no Brasil. Mem. Inst. Oswaldo Cruz, $11: 121-55,1919$.

15. MAGALHĀES, L.A. Moluscos planorbideos do Distrito Federal, Brasilia. São Paulo, 1966. [Tese de Doutoramento - Faculdade de Medicina da Universidade de Campinas].

16. MAGALHAES, L.A.; ALCÁNTARA, F.G. \& CARVALHO, J.F. Alguns dados referentes ao estudo parasitológico e anatomopatológico de duas linhagens de Sohistosoma mansoni Sambon 1907. Rev. Saúde públ., S. Paulo, 9:1-5, 1975.

17. MAGALHAES, L.A. \& CARVALHO, J.F. Desenvolvimento do Schistosoma mansoni das linhagens de Belo Horizonte (MG) e de São José dos Campos (SP) em Mus musculus. Rev. Saúde públ., S. Paulo, $7: 285-7,1973$.

18. MAGALHĀES, L.A. \& CARVALHO, J.F. Estudo morfológico de Schistosoma mansoni pertencentes a linhagens de Belo Horizonte (MG) e de São José dos Campos (SP). Rev. Saúde públ., S. Paulo, 7:289-94, 1973. 
GUARALDO, A.M.A. et al. Evolução dos esporocistos de Schistosoma mansoni Sambon, $1907 \mathrm{em}$ Biomphalaria glabrata (Say, 1818) e Biomphalaria tenagophila (D'Orbigny, 1835). Rev. Saride públ., S. Paulo, 15:436-48, 1981.

19. Magalhies, L.A. \& CARVALHO, J.F. Determinação do número de cercárias provenientes de cepas diferentes de Schistosoma mansoni que conseguem penetrar, sob determinadas condiçzes de laboratório, em Mus musculus. Rev. Soc. bras. Med. trop., 3:249-51, 1969.

20. MALDONADO, J.F. \& ACOSTA-MATIENZO. J. The development of Schistosoma mansoni in the snail intermediate host, Australorbis glabratus. Puerto Rico J. Hith trop. Med., 22: 331-73, 1947.

21. MARTINS, R.S. Focos ativos de esquistossomose em Niterói, Estado do Rio de Janeiro. Rev. bras. Malar, 9:361-4, 1957.

22. MOURA, S.A.L. Esquilstossomose mansoni autóctone em Santos. Rev. Inst. Adolfo Lutz, $5: 279-311,1945$.

23. NEWTON, W.L. The comparative tissue reaction of two strains of Australorbis glabratus to infection with Sohistosoma mansoni. J. Parasit., 38:362-6, 1952.

24. NEWTON, W.L. The inheritance of s:sceptibility to infection with schistosoma mansoni in Australorbis glabratus. Exp. Parasit., 2:242-57, 1953.

25. NEWTON, W.L. Tissue responses to Schistosoma mansoni in second generation snalls from a cross between two strains of Australorbis glabratus. J. Parasit., $40: 352-5,1954$.

26. OLIVER, L. \& MAO, C. The early larval stages of Schistosoma mansoni Sambon, 1907 in the snail host. Australorbis glabratus (Say, 1818). J. Parasit., $35: 267-75, \quad 1949$.

27. PAN, C.T. Generaltzed and focal tissue response in the snail Australorbis glabratus, Infected with Schistosoma mansoni. Ann. N.Y. Acad. Sci., 113:475-85. 1963.

28. PAN, C.T. Studies on the host-parasite relationship between Schistosoma mansoni and the snall Australorbis glabratus. Amer. J. trop. Med. Hyg., 14:981-76, 1965.

29. PARAENSE, W.L. \& CORRRA, L.R. Differential susceptibility of Biomphalaria tenagophita populations to infection with a strain of Schistosoma mansoni. J. Parasit., 64:822-6, 1978.
30. PARAENSE, W.L. \& CORREA, L.R Sobre a ocorrência de duas raças blológicas do schistosoma mansoni no Brasil. Cienc. Cult., 15:245-6, 1963.

31. PARAENSE, W.L. \& CORRAA, L.R. Susceptibllity of Australorbis tenagophilus to infection with Sohistosoma mansoni. Rev. Inst. Med. trop. S. Paulo, 5:23-9, 1968.

32. Paraense, W.L. \& CoRrei, L.R. Variation in susceptibility of populations of Australorbis glabratus to a strain of Schistosoma mansoni. Rev. Inst. Med. trop. S. Paulo, 5:15-22, 1963.

33. PIZA, J.T.; RAMOS, A.S.; BRANDAO, C.S.H. \& FIIGUEIREDO, C.G. A esquistossomose no Vale do Paraíba. Observaçós sobre a doença em alguns dos seus municipios e a fauna planorbidica da Região. Rev. Inst. Adolfo Lutz, 19: 97-143, 1959.

34. RICHARDS, C.S. \& MERRITT Jr., J.W. Genetic factors in the susceptibility of juvenile Biomphalaria glabrata to Schistosoma mansoni infection. Amer. J. trop. Med. Hyg., $21: 425-34,1972$.

35. RICHARDS, C.S. Susceptibility of adult Biomphalaria glabrata to Schistosoma mansoni infection. Amer. J. trop. Med. Hyg., 22 :748-56, 1973.

36. SANTANA, J.V.; MAGALHAES, L.A. \& RANGEL, H.A. Seleção de linhagens de Biomphalaria tenagophila e Biomphalaria glabrata visando maior suscetibilidade ao Schistosoma mansoni. Rev. Saúde públ., S. Paulo, $12: 67-77.1978$.

37. SNEDECOR, G.W. \& COCHRAN, W.G. Statistical methods. 6th ed. Ames, Iowa, lowa State University Press, 1967.

38. TRIPP, M.R. The fate of forelgn materials experimentally introduced into the snail Australorbis glabratus. J. Parasit., 47: 747-51, 1961.

39. TRIPP, M.R. Defense mechanism of molluscs. J. reticuloendothel. Soc., $7: 173-82$, 1970.

40. TRIPP, M.R. Molluscan Immunity Ann. N.Y. Acad. Sci., 234:23-7. 1974.

Recebido para publicagão em 06/02/1981 Aprovado para publicagáo em 11/0s/1981 